\title{
Posttraumatic Aneurysm of a Patent Umbilical Vein: Diagnosis and Specific Treatment
}

\author{
Matthias Grade, MD, DTM\&H, FEBG ${ }^{1}$ Siegfried Krishnabhakdi, MD ${ }^{2}$ Thomas Vestring, MD $^{3}$ \\ Micha Löbermann, $\mathrm{MD}^{4}$ Joachim Conrad Arnold, MD
}

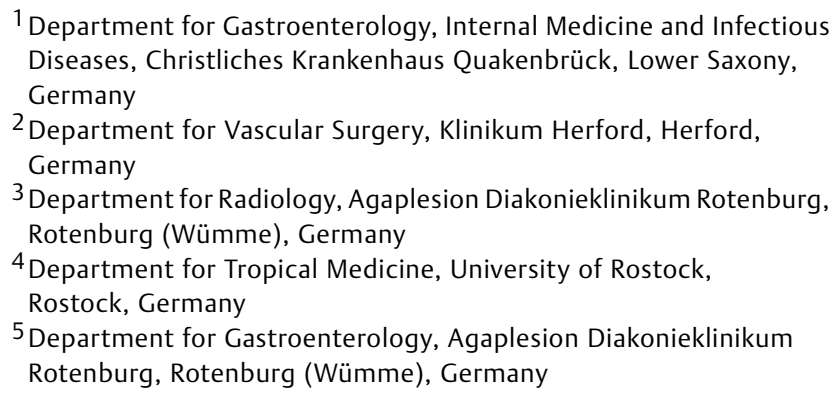

Address for correspondence Matthias Grade, MD, DTM\&H, FEBG, Department for Gastroenterology, Internal Medicine and Infectious Diseases, Christliches Krankenhaus Quakenbrück, Danziger Str.2, 49610 Quakenbrück, Lower Saxony, Germany (e-mail: m.grade@ckq-gmbh.de).

Surg J 2017;3:e113-e116.

\begin{abstract}
Keywords

- liver cirrhosis

- patent paraumbilical vein

- posttraumatic aneurysm

- TIPS

A patent umbilical vein is a rare condition in healthy volunteers, but can be detected in up to $11 \%$ of patients with liver cirrhosis as a consequence of portal hypertension. We report the case of a 52-year-old woman who was admitted to our department with acute abdominal pain after blunt trauma to her forehead and abdomen. She had a history of alcohol abuse with liver cirrhosis that had been classified as Child-Pugh stage C 5 years earlier. Signs of portosystemic shunting had been present at an earlier endoscopy, and esophageal varices were found.

Clinical examination revealed typical signs of liver cirrhosis, and ultrasound examination showed an aneurysm of $6 \mathrm{~cm}$ of the umbilical vein, which had not been present at earlier examinations. After lowering portal hypertension by inserting a transjugular intrahepatic portosystemic shunt, an open surgical resection of the aneurysmal umbilical vein was performed without complications. The patient recovered well and was discharged from the hospital 10 days later.

We hypothesize that the abdominal trauma prompted or aggravated umbilical vein aneurysm in this patient with liver cirrhosis and portal hypertension. Due to the risk of rupture, a surgery-based resection is a valuable treatment option.
\end{abstract}

In adults, a patent paraumbilical vein is associated with portal hypertension in liver cirrhosis, independently of the underlying cause of cirrhosis. The main etiologies of hepatic cirrhosis in Western countries are alcohol abuse, ${ }^{1,2}$ viral hepatitis B or C, and nonalcoholic steatohepatitis. ${ }^{3}$ In comparison to other causes of cirrhosis, alcohol abuse seems to be the most common.

A morphological enlargement of an arterial vessel is formally known as an aneurysm. The critical diameter, especially in the abdominal aorta, is estimated to be $5 \mathrm{~cm},{ }^{4}$ but as other risk factors such as annual growth rate are cofactors in deterioration, these should also lead to interventional vascular procedures (operation, stenting, coils, etc.).

An enlargement of a venous vessel is described clinically as a patency, a pseudoaneurysm, or an aneurysmal dilatation. Modification in hemodynamic parameters such as increased portosystemic pressure and portal hypertension in cirrhotic liver tissue are frequently seen. ${ }^{5}$ received

November 26, 2016 accepted after revision May 24, 2017
DOI https://doi.org/ 10.1055/s-0037-1604075. ISSN 2378-5128.
Copyright $\odot 2017$ by Thieme Medical Publishers, Inc., 333 Seventh Avenue, New York, NY 10001, USA. Tel: +1(212) 584-4662.
License terms

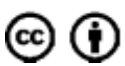


In addition to that, paraumbilical vein patency (PUV) is a clinical disorder with a high rate of severe complications and can found in patients with liver cirrhosis and portal hypertension.

We present the first recorded case of a woman with a PUV in liver cirrhosis following blunt abdominal trauma.

\section{Case Report}

A 52-year-old woman with a long history of alcohol abuse presented to our hospital with trauma to her head and abdomen after domestic violence, complaining of persistent pain in her lower right abdomen. She had a history of alcoholic liver cirrhosis that had been classified as ChildPugh stage C. In the past, she suffered from esophagus variceal bleeding that had been successfully treated by band ligation.

\section{Physical State}

Physical examination revealed an ocular hematoma on the left eye and numerous hematomas all over the abdomen, mainly in the paraumbilical and lower regions. There were clinical signs of ascites. Body weight was $68 \mathrm{~kg}$, height was $168 \mathrm{~cm}$, and body mass index was 24 . There were no specific neurologic findings and no signs of hepatic encephalopathy.

\section{Laboratory Results on Admission}

Routine laboratory tests revealed normal full blood count. Platelets were $31 / \mathrm{nL}$ (normal range: $150-350 / \mathrm{nL}$ ), and hemoglobin was $8.2 \mathrm{~g} / \mathrm{dL}$ (normal range: $12-16 \mathrm{~g} / \mathrm{dL}$ ).

Sodium 128 was $\mathrm{mmol} / \mathrm{L}$ (normal range: $135-145 \mathrm{mmol} / \mathrm{L}$ ), potassium was $3 \mathrm{mmol} / \mathrm{L}$ (normal range: $3.5-4.5 \mathrm{mmol} / \mathrm{L}$ ), and calcium was $2.09 \mathrm{mmol} / \mathrm{L}$ (normal range: $2.1-2.5 \mathrm{mmol} / \mathrm{l}$ ).

Signs of decreased liver function due to liver cirrhosis were detected: bilirubin was $6.90 \mathrm{mg} / \mathrm{dL}$ (normal range: $<1.2$ ), GOT (AST) was $69 \mathrm{U} / \mathrm{L}$ (normal range: $<32$ ), GPT (ALT) was $33 \mathrm{U} / \mathrm{L}$ (normal range: <33), GGT was $532 \mathrm{U} / \mathrm{L}$ (normal range: 6-42), choline esterase was $3.18 \mathrm{kU} / \mathrm{L}$ (normal range: 5.3-12.9). LDH was $355 \mathrm{U} / \mathrm{L}$ (normal range: $<250$ ), C-reactive protein was $1.2 \mathrm{mg} / \mathrm{dL}$ (normal range: $<0.5 \mathrm{mg} / \mathrm{L}$ ).

Liver coagulation parameters: INR was 1.53(normal range 1-1.5), and PTT was 35.6 second (normal range: 24-33 seconds).

\section{Physical Examinations and Interventional Procedures} An abdominal ultrasound examination immediately after hospital admission detected liver cirrhosis with a moderate amount of ascites (normal light yellow ascites with no signs of spontaneous bacterial peritonitis with neutrophil count $<250 / \mathrm{mm}^{3}$ ), and an enlarged vessel with aneurysm-like ballottement over an area of 5 to $6 \mathrm{~cm}$ near the paraumbilical region. The vessel was identified as the patent umbilical vein (-Figs. 1 and 2).

Treatment of the aneurysm was indicated due to the patient's unstable social environment, which put her at risk of recurrent blunt traumata and potentially fatal bleeding. Voluminous abdominal wall collaterals made a laparoscopic

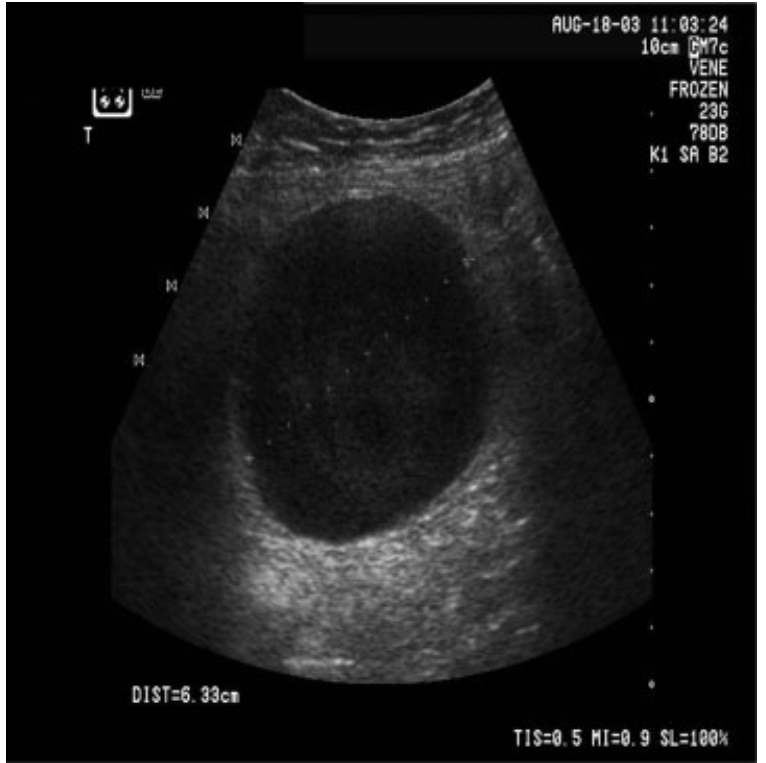

Fig. 1 Under ultrasound examination, an echo-poor formation can be identified as a vessel.

approach inappropriate. As a result, a team of gastroenterologists, surgeons, and interventional radiologists met to discuss the most appropriate procedure. In the light of the patient's elevated bilirubin levels $(6.9 \mathrm{mg} / \mathrm{dL})$, and fearing the spontaneous rupture of the aneurysm, the decision was taken to lower portal pressure. The implantation of a transjugular intrahepatic portosystemic shunt (TIPS; - Fig. 3a, b) seemed to be the least invasive option. Apart from thrombocytopenia and elevated bilirubin, contraindications for TIPS implantation (hepatic encephalopathy, portal thrombosis, heart insufficiency, pulmonal hypertension, etc.) could be ruled out.

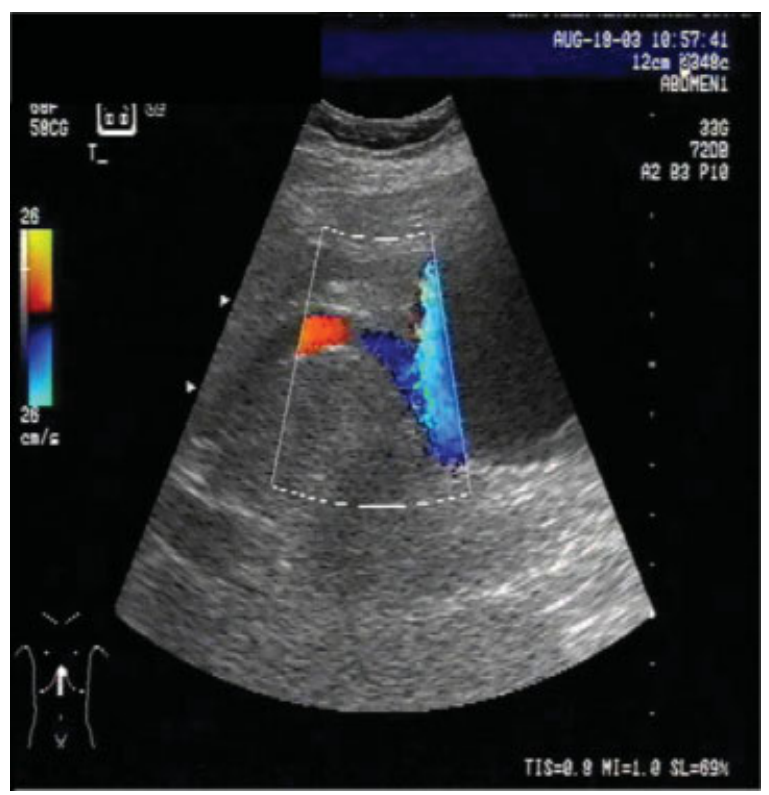

Fig. 2 In the power Doppler mode, the superficial abdominal varices are clearly visible. 


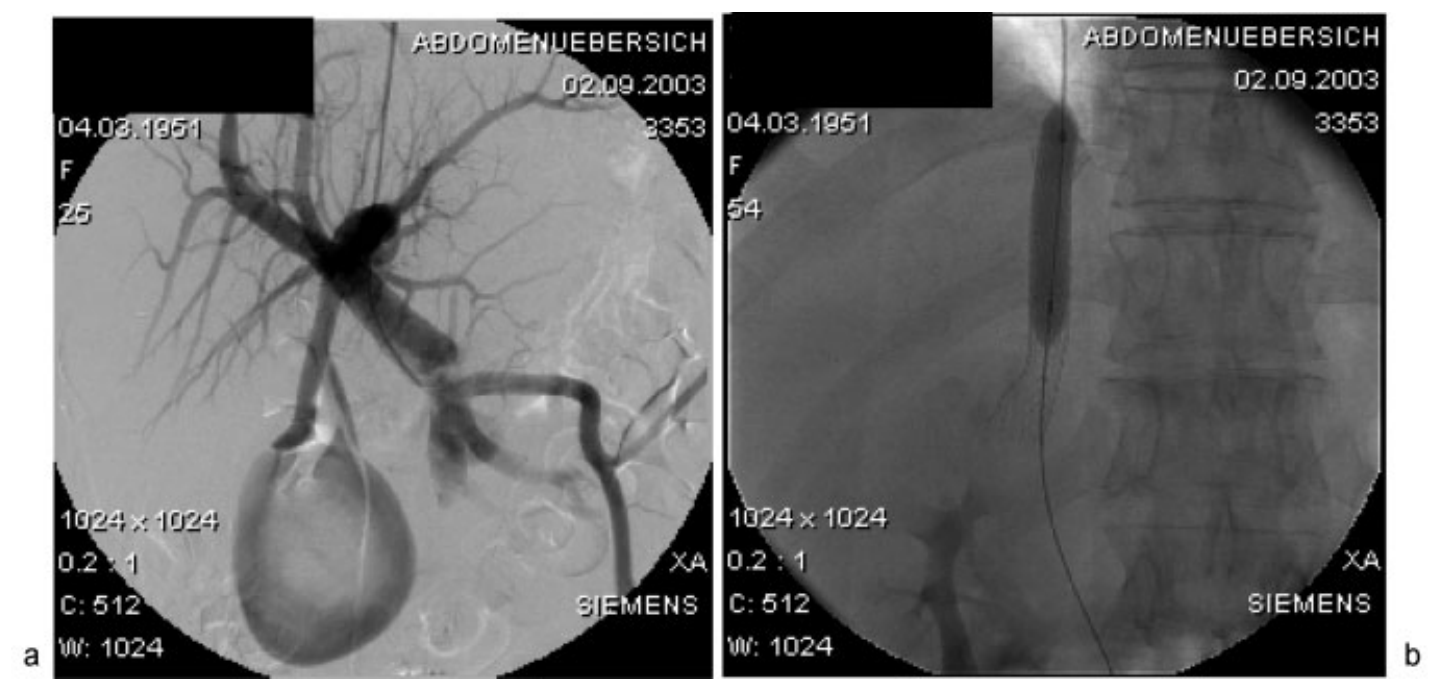

Fig. 3 (a) Transjugular intrahepatic portosystemic shunt (TIPS) (b) Due to the presence of esophageal varices and a patent umbilical vein, a TIPS was implanted before surgical correction commenced to reduce the portovenous pressure and to minimize the risk of intraoperative bleeding.

\section{Transjugular Intrahepatic Portosystemic Shunt Procedure}

The TIPS maneuver was performed in a standard fashion through the right jugular vein. Following intrahepatic portal vein puncture, the direct portography revealed a $5.8 \times 7 \mathrm{~cm}$ large aneurysm of the patent umbilical vein. For TIPS creation, the parenchymal tract was dilated using a $7-\mathrm{mm}$ angioplasty balloon followed by placement of a $12-\mathrm{mm}$ bare stent (Memotherm-TIPS, BARD GmbH, Karlsruhe, Germany). Depending on the portosystemic gradient, balloon dilation of the stent was successively performed from 7 to $9 \mathrm{~mm}$. Following 9-mm angioplasty, the portosystemic pressure gradient dropped from $24 \mathrm{~mm} \mathrm{Hg}$ before the procedure to $13 \mathrm{~mm} \mathrm{Hg}$ after the procedure.

Due to persisting aneurysm after TIPS procedure visible in ultrasound examination, and regarding the patient's social back- ground and the volatility of her personal situation after hospital discharge, a complete surgical removal of the aneurysm was

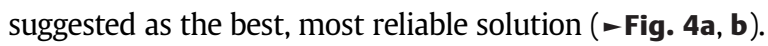

\section{Surgical Procedure}

During the operation, the aneurysm was exposed by a midline incision (-Fig. 4a), and the large abdominal wall vessels were ligated. The patent umbilical vein was resected from the umbilicus to the interlobular level close to the portal vein ( - Fig. 4b). Unusual adhesions to the falciform ligament and the gallbladder, combined with the thinness of the aneurysm wall, made preparation extensive and demanding and encouraged the theory of traumatic origin.

The resected vessel was incised longitudinally, and the aneurysm was identified as a combined saccular and fusiform type (-Fig. 4b). The abdominal cavity was closed

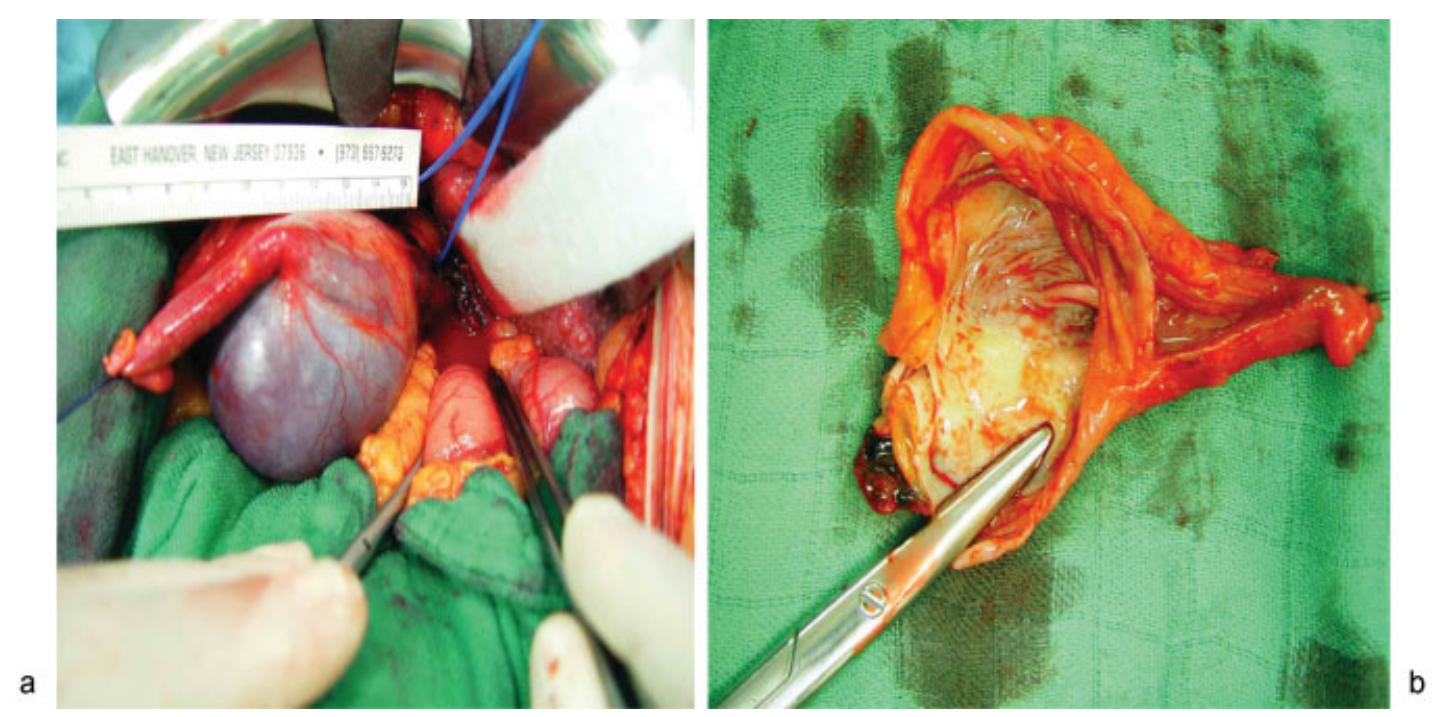

Fig. 4 Intraoperative findings. (a) The paraumbilical vein patency is ligated but still in situ. (b) Typical combined saccular and fusiform-type aneurysm. 
without drainage after meticulous bleeding control. Overall blood loss was minimal.

The patient was discharged 10 days after operation in good condition and put on a withdrawal and rehabilitation program.

\section{Discussion}

This clinical case focuses on the controversial question of interventional procedures in cases of aneurysm of the umbilical vein. A review of the literature indicates that a posttraumatic origin of an umbilical vein aneurysm has never been described to date. Although we have no direct proof that the physical violence exerted by the patient's partner actually caused the aneurysmatic enlargement to develop, but the theory seems to be credible. A histopathology of the resected aneurysm was not proposed unfortunately. The last laparoscopic examination performed 2 years earlier in our endoscopic unit showed no signs of aneurysm. The port of the laparoscopic device was placed at Kalk's point in the left midabdomen at that time, clarifying the cirrhotic liver situation.

To avoid a spontaneous rupture, for example, a rupture during resection, our aim was to reduce portovenous pressure to lower levels.

The patient already had spontaneous bleeding from esophageal varices. After discussion with the patient and assurances of her intention to make changes in her personal life (agreement to embark on an alcohol withdrawal and rehabilitation program), we took the decision to perform a vascular surgical correction of the aneurysm.

Due to the high risk of intraoperative bleeding complications, a TIPS was implanted before surgery. TIPS implantation in cirrhotic patients started in 1988 as an alternative to surgery-based shunting procedures. Nowadays, TIPS is an established form of treatment that has been shown to increase survival in patients with end-stage liver cirrhosis. ${ }^{6-8}$
In conclusion, this rare case demonstrates the impact of violent acts to the special liver tissue system in cirrhotic alcohol-addicted patients.

The patient ultimately recovered well. At the time of discharge, she was free of ascites and was able to embark on her chosen withdrawal therapy.

Outlook and patient-related procedure: after withdrawal therapy, endoscopic checks for esophageal varices and ultrasound examinations of the TIPS will be performed on a regular basis. The cirrhotic situation will be kept under strict control in the outpatient department of the liver unit.

\section{References}

1 Chen $\mathrm{CH}$, Wang JH, Lu SN, et al. Comparison of prevalence for paraumbilical vein patency in patients with viral and alcoholic liver cirrhosis. Am J Gastroenterol 2002;97(09):2415-2418

2 Zardi EM, Uwechie V, Caccavo D, et al. Portosystemic shunts in a large cohort of patients with liver cirrhosis: detection rate and clinical relevance. J Gastroenterol 2009;44(01):76-83

3 Altinbas A, Sowa JP, Hasenberg T, Canbay A. The diagnosis and treatment of non-alcoholic fatty liver disease. Minerva Gastroenterol Dietol 2015;61(03):159-169

4 Chang JB, Stein TA, Liu JP, Dunn ME. Risk factors associated with rapid growth of small abdominal aortic aneurysms. Surgery 1997; 121(02):117-122

5 Jalan R, Hayes PC. British Society of Gastroenterology. UK guidelines on the management of variceal haemorrhage in cirrhotic patients. Gut 2000;46(Suppl 3-4):III1-III15

6 European Association for the Study of the Liver. EASL clinical practice guidelines on the management of ascites, spontaneous bacterial peritonitis, and hepatorenal syndrome in cirrhosis. J Hepatol 2010;53(03):397-417

7 Fujimoto J. Gene therapy for liver cirrhosis. J Gastroenterol Hepatol 2000;15(Suppl):D33-D36

8 Hara Y, Sato Y, Yamamoto S, et al. Successful laparoscopic division of a patent ductus venosus: report of a case. Surg Today 2013; 43(04):434-438 